\title{
AS ANTOLOGIAS ORGANIZADAS PELA ESCRITORA HENRIQUETA LISBOA NAS DÉCADAS DE 1960 E 1970 1
}

\author{
Ana Lúcia Maria de Souza Neves *
}

\begin{abstract}
Resumo: O presente artigo reflete sobre as antologias de poemas organizadas nas décadas de 1960 e 1970 pela escritora mineira Henriqueta Lisboa. O objetivo principal do trabalho é destacar o pioneirismo das ideias da escritora e verificar possíveis contribuições destas ideias para discussões atuais sobre a utilização da antologia nas aulas de literatura. Dentre as ideias de Henriqueta Lisboa, destacamos: a visão acerca da antologia como um instrumento para a "formação estética" da criança e do jovem; a ênfase na leitura do texto literário em detrimento do estudo da historiografia priorizado na época; a observação do interesse do leitor como critério para a seleção dos textos; a organização da antologia invertendo a linearidade cronológica, em vez de selecionar os autores e as obras do passado para o presente, ao contrário, a autora parte das obras contemporâneas para as mais antigas; abertura para autores e obras contemporâneos.
\end{abstract}

Palavras-Chave: Antologia. Henriqueta Lisboa. Texto literário. Escola.

\begin{abstract}
The anthologies of the poems written by Henriqueta Lisboa in the decades of 1960 and 1970 are discussed in this paper. The main goal of this work is to highlight the pioneering spirit of the ideas of the writer and check possible contributions of these ideas to current debates about the use of anthologies in literature classes. Among the ideas of Henriqueta Lisboa, we highlight: the vision about anthology as a tool for the "aesthetic education" of the child and the young; the emphasis on reading the literary text at the expense of the study of historiography prioritized at the time; the observation of the reader's interest as a criterion for the selection of the texts; the organization of an anthology by reversing the chronological linearity ( instead of selecting the authors and the works of the past to the present, the author starts from the contemporary works to the earliest ones); the opening for contemporary authors.
\end{abstract}

Keywords: Anthology, Henriqueta Lisboa. Literary Text. School.

\section{Introdução}

A escritora mineira Henriqueta Lisboa, assim como muitas mulheres escritoras de sua época, dedicou-se ao magistério, atuando como professora e produzindo obras direcionadas ao público infantil e juvenil. No artigo "Mulheres escrevem para criança (18901930)", de Rosa Maria de Carvalho Gens (2003), são apontados três nomes de escritoras brasileiras que se dedicaram do final do século XIX até meados do século XX à produção de obras destinadas ao público infantil. Encontramos referência aos nomes de Júlia Lopes de Almeida (1862-1934); Emília Moncorvo Bandeira de Mello Vasconcellos (1852-1911), que usava o pseudônimo de Carmem Dolores; e Cecília Bandeira de Melo (1870-1948), que assinava as obras sob o pseudônimo de Chysanthème.

Segundo Gens (2003), nas obras das escritoras citadas, a representação da infância encontra-se circunscrita e conduzida pelo tom pedagógico. A literatura infantil é escrita visando atender aos anseios da sociedade da época marcada pelos ideais de nacionalização e modernização:

Ao final do século XIX, forte é a corrente positivista que deseja a condução de comportamentos e a literatura destinada a crianças torna-se excelente

\footnotetext{
${ }^{1}$ Este artigo é uma versão modificada do capítulo da minha tese Henriqueta poetisa e educadora: a poesia a favor da educação estética. $\mathrm{O}$ título da tese é "Um atalho, uma clareira, coisa assim no caminho": reflexões sobre os lugares de Henriqueta Lisboa no contexto da literatura brasileira.

Professora do Departamento de Letras e Artes da Universidade Estadual da Paraíba. E-mail: analiteraturasouza@yahoo.com.br
} 
veículo para marcar os contornos dos comportamentos desejados. Tratavase, nessa primeira leva de livros infantis que podem ser considerados como brasileiros, de produzir perfis de crianças que se adaptassem ao padrão almejado. Assim, a ênfase recaía em formar comportamentos condizentes com o que se entendia por criança. O escopo das obras situa-se na função de educar, harmonizando-se com a tarefa de educadoras que cabia às mulheres. Seres que educam e outros que existem no mundo para serem educados estava feita a dobradinha que vai permitir o desenvolvimento de uma imagem de escritora ligada ao público infantil.

Diferente das autoras estudadas por Gens (2003), ao escrever poemas tematizando a infância, redigir ensaios sobre a relação entre poesia e educação e organizar antologias para crianças e jovens, Henriqueta Lisboa recorre à concepção de educação estética em um sentido mais amplo. Educar esteticamente para Henriqueta não se limita ao estabelecimento de modos de agir, pensar e sentir de acordo com o instituído pela sociedade burguesa. Para a escritora mineira, a poesia ensina ao fazer o leitor refletir criticamente sobre si mesmo e sobre o mundo no qual está inserido, sem perder a sensibilidade. Em suas entrevistas, prólogos e ensaios Henriqueta mostra-se a educadora preocupada com a formação estética e cultural de crianças e jovens no Brasil, bem como o compromisso da artista que via na arte, e mais especificamente na literatura, um meio fundamental para o florescimento da sensibilidade, da imaginação e da criticidade do leitor. É assim que se expressa Henriqueta ao comentar o livro O peixe e o pássaro, de Bartolomeu Campos de Queirós:

O mundo - principalmente o das crianças - precisa contaminar-se de cores em transparência, fluidez de linguagem, delicadeza de dicção, sobriedade expressiva e magia musical, qualidades presentes no poema em questão. As crianças devem - mais do que em geral se presume e hoje mais do que nunca - encontrar uma faixa de relacionamento e equilíbrio em que se harmonizem seus sentidos e sonhos, entre as sombras do ignorado e os vislumbres do pressentido. (LISBOA, 1974, p.1). definitivo:

Para Henriqueta, poesia não tem destinatário, no sentido de algo limitador,

Como todas as grandes cousas verdadeiras, a poesia é uma só. Uma só cousa - vasta, profunda, total. Que subsiste através de rótulos, desconhece divisões, emerge de departamentos e escolhas. Que não se atém a capacidade ou incapacidade de apreensão alheia, nem sequer a necessidades outras que não a sua própria necessidade de existir. (LISBOA, 1955, p.87-88).

As palavras de Henriqueta se referem ao fenômeno poético como aspecto humano e artístico que precisa ser considerado sempre de maneira plena. Logo, para Henriqueta, a poesia, considerada como obra de arte, não deve ser acompanhada de adjetivo restritivo (poesia infantil, juvenil, adulta), pois, na realidade, a "verdadeira" poesia não se limita a rótulos. No ensaio intitulado "Poesia e didática" afirma:

Adjetivos ao lado da palavra poesia são geralmente supérfluos. Limitam-se quando muito há um círculo de sistema, como, por exemplo, na expressão "poesia didática". Em rigor, poesia didática deixa de ser poesia pela razão de ser didática, ou melhor, por ter uma finalidade que não se enquadra no jogo poético. (LISBOA, 1955, p.57). 
Para a poetisa, "é por engano que se empresta à poesia a função de ensinar." (LISBOA, 1955, p.57). Segundo ela, a poesia "poderá ensinar, porém acidentalmente, desde que o elemento lírico se sobreleve ao enunciado filosófico ou científico (...) ensinará, pois, com a vida, de modo implícito e possivelmente melhor do que a escola." (LISBOA, 1955, p. 58).

Ao todo Henriqueta organizou quatro antologias para a infância e a juventude: Antologia poética para a infância e a juventude (1961); Literatura oral para a infância e a juventude (1969); Antologia escolar de poemas para a juventude (s/d); Antologia de poemas portugueses para a juventude (2005). ${ }^{2}$ Estas obras que começaram a ser publicadas no início da década de 1960 revelam concepções de poesia, relação entre texto e leitor, ensino da literatura, dentre outras. Antes de discutimos acerca das concepções presentes nas antologias, realizaremos uma apresentação de cada uma das quatro obras.

\section{Apresentação das antologias}

A Antologia Poética para a Infância e a Juventude (1961) encontra-se dividida em duas partes, a primeira voltada para a criança e a segunda para o jovem. Em ambas as seções, parte-se de autores e de obras de "data contemporânea para tempos mais remotos": modernos, simbolistas, parnasianos românticos (na segunda parte do livro são inseridos poetas árcades e clássicos). Subsequente a cada uma das partes, são apresentados poemas traduzidos, a maioria de autores hispano-americanos.

A obra Literatura oral para a infância e a juventude (1969), reeditada pela Peirópolis em 2002 e enviada para as escolas públicas de todo país em 2005, através do PNBE (Programa Nacional Biblioteca Escolar), é uma coletânea de lendas, contos e fábulas populares do Brasil. A obra apresenta também, na seção intitulada "Bibliografia", a relação dos autores, livros e documentos de onde foram resgatados os textos, constituindo-se em uma fonte rica para pesquisadores da atualidade. A edição mais recente apresenta prefácio e ilustrações de Ricardo Azevedo que assinala o valor da antologia devido, dentre outros aspectos, reunir textos colhidos em fontes completamente esgotadas e fora de catálogos atualmente.

A Antologia escolar de poemas para a juventude, publicada pela Ediouro, reúne poemas presentes na segunda parte da Antologia Poética para a Infância e a Juventude (1961). O prólogo, escrito pela organizadora, constitui-se uma parte importante da antologia, uma vez que encontramos o critério de seleção e apresentação dos textos, formas de abordagens do texto literário pela escola, dentre outros aspectos. A obra apresenta também a seção "Notas biográficas" com informação sobre os autores e a fonte de onde foram recolhidos os poemas.

$\mathrm{Na}$ Antologia de poemas portugueses para a juventude (2005), são contemplados poemas escritos pelos poetas portugueses Fernando Pessoa, Alfonso Lopes Vieira, Armindo Rodrigues, Augusto Gil, Gomes Leal, Antônio Nobre, João de Deus, Carlos Queirós, Branquinho da Fonseca, José Régio, Miguel Torga, Florbela Espanca, Antero de Quental, Guerra Junqueiro, Almeida Garrett, Tomás Antônio Gonzaga, José de Anchieta, Rodrigues Lôbo, Luis de Camões. A antologia foi publicada pela editora Peirópolis a partir dos poemas incluídos por Henriqueta Lisboa na Antologia Poética para a Infância e a Juventude (1961).

\footnotetext{
${ }^{2}$ As coletâneas Antologia escolar de poemas para a juventude (s/d) e Antologia de poemas portugueses para a juventude (2005) foram compostas a partir da Antologia poética para a infância e a juventude (1961).
} 
A obra é prefaciada pelo escritor Bartolomeu Campos de Queirós, grande amigo e admirador de Henriqueta Lisboa.

\section{Sobre os prefácios e prólogos}

Nas primeiras edições das antologias organizadas por Henriqueta Lisboa não aparecem prefácios, dessa forma o leitor não tem acesso a impressões de terceiros sobre as obras. A ausência de prefácios marca também os livros de ensaios da autora. Dos quatro publicados, apenas dois apresentam prefácios. ${ }^{3}$ Este aspecto mostra-se importante, tendo em vista que estamos concebendo os prefácios, assim como os prólogos, elementos de significação, por trazerem informações que são indispensáveis na operação de leitura. A ausência de prefácios impõe um silêncio sobre a autora e a sua obra.

Em comemoração ao centenário de nascimento da poetisa em 2001, alguns dos seus livros começaram a ser reeditados, a exemplo das antologias Literatura Oral para a Infância e a Juventude (2002) e Antologia de poemas portugueses para a juventude (2005). Nestas edições encontramos respectivamente os prefácios de Ricardo Azevedo e Bartolomeu Campos de Queirós.

Apesar de apresentarem diferenças, principalmente, porque se referem a coletâneas de textos de gêneros diferentes, os discursos de Azevedo e Queirós revelam certas recorrências no que diz respeito à autora e às suas obras.

De acordo com Azevedo (2002), o livro de Henriqueta é pioneiro e se constitui em valioso documento:

É preciso, antes de mais nada, apontar o caráter pioneiro do livro Literatura oral para a infância e a Lisboa juventude, por Henriqueta idealizado por Henriqueta Lisboa na década de 50. Trata-se de uma coletânea de mitos, lendas, contos populares e fábulas feitas a partir do trabalho de vários e importantes pesquisadores. A obra contempla narrativas de tradição europeia, africana e indígena. Se hoje, mesmo diante de uma sólida e sedimentada indústria editorial, os leitores têm tido pouco acesso a textos desse tipo, é de supor que a cinquenta anos a situação não fosse diferente. [...] Note-se que boa parte das obras consultadas está hoje completamente esgotada e fora de catálogo, o que torna o livro um documento valioso. (AZEVEDO, apud LISBOA, 2002, p.9).

Queirós (2005) assinala a singularidade da antologia que apresenta para o jovem a "melhor" poesia portuguesa:

[...] Henriqueta Lisboa visita os poetas de Portugal - marco inicial da nossa cultura - e recolhe o melhor da poesia ali existente para oferecer aos nossos jovens. E, por sua escolha, ela nos confirma mais um de seus critérios: a arte não tem fronteiras. Por nascer da emoção e ser recebida com emoção, ela se faz propícia a todos, reduzindo distância e aproximando os homens, tendo como instrumento a beleza. (QUEIRÒS, apud LISBOA, 2005, p.7).

Percebemos que para Azevedo e Queirós as antologias organizadas por Henriqueta reúnem, consagram e conservam, a nosso ver, no entanto, além de arquivamento, representam

\footnotetext{
3 As coletâneas de ensaios publicados por Henriqueta Lisboa que apresentam prefácios são: Alphonsus de Guimaraens (1945), prefaciada por Gustavo Capanema e Vivência Poética, prefaciada por Pe. Lauro Palú.
} 
um procedimento crítico, pois revelam, antes de tudo, uma operação de escolhas. Além de selecionar e reunir, as antologias interpretam e instituem, ou seja, há elementos sobre os quais são atribuídos valor e outros que são deixados de lado. Estes elementos podem ser observados no discurso de Henriqueta presente no prólogo das obras. ${ }^{4}$

\subsection{As antologias e a educação estética das crianças e dos jovens}

$\mathrm{Na}$ antologia Literatura oral para a infância e a juventude: lendas, contos e fábulas populares no Brasil (1969), Henriqueta apresenta uma avaliação crítica dos livros produzidos e consumidos neste período pelos jovens:

Os livros que lêem comumente os meninos de hoje, de aventuras inverossímeis, traduzidos em massa para o vernáculo, excitam a fantasia porém não alimentam a imaginação. A primeira é tão-somente um jôgo (sic) eventual; a segunda, o dom de intuir e inventar novas formas sôbre (sic) os fundamentos do real e do autêntico. (LISBOA, 1969, p.12).

No trecho citado, além de demonstrar conhecimento sobre a realidade da produção literária no Brasil durante as décadas de 1940 a 1960. Henriqueta estabelece a distinção entre fantasia e imaginação. Esta distinção está fundamentada na concepção de Schiller da "terceira via de conhecimento", por meio da qual o homem poderia viver sem estar preso à vida material nem tampouco a uma existência somente ideal. Sem escapar totalmente da realidade, como seria característico da fantasia, pela imaginação o homem não perderia a simplicidade da natureza, "o autêntico", e garantiria o equilíbrio entre razão e sensibilidade.

Henriqueta, conforme atestam as suas palavras, ao ler a Educação Estética do Homem, identificou-se profundamente com as ideias do filósofo alemão. A influência da obra em sua vida é reiterada pela poetisa em diversas conferências e entrevistas. Na conferência "Poesia: minha profissão de fé", proferida em 1978 e incluída em 1979 no livro de ensaios Vivência Poética, declara:

E aqui deixo a lembrança de um pensamento de Schiller, que exerceu grande influência na minha formação, através de seu livro sobre educação estética: "Se nos entregamos ao gozo da verdadeira beleza, então somos, naquele momento, donos em igual proporção de nossas potências ativas e passivas; com a mesma suma ligeireza nos entregamos à seriedade e ao jogo, ao repouso e ao movimento, à condescendência e à reação, ao pensamento instintivo e ao absoluto". (LISBOA, 1979, p.22).

O trecho citado por Henriqueta corresponde a um recorte das palavras de Schiller presente na carta XXII na qual o filósofo reflete sobre o tratamento dado à arte a partir da obra, do artista (o ato de produção) e do apreciador. Na passagem citada por Henriqueta, Schiller ressalta a importância da educação estética, afirmando que só por meio dela o homem poderá desenvolver-se plenamente, tanto em suas capacidades intelectuais quanto sensíveis. No "impulso lúdico", razão e sensibilidade atuam juntas e não se pode mais falar da tirania de uma sobre a outra. Através do belo, o homem é como que recriado em todas as suas

\footnotetext{
${ }^{4}$ Estamos utilizando o termo prólogo em referência ao texto introdutório escrito pela própria organizadora. Nas antologias organizadas por Henriqueta, encontramos prólogo nas obras: Antologia Poética para a Infância e a Juventude (1961), Literatura Oral para a Infância e a Juventude (1969; 2002) e Antologia Escolar para a Infância e a Juventude (s/d).
} 
potencialidades e recupera sua "liberdade" tanto em face das determinações do sentido quanto em face das determinações da razão. Pode-se afirmar, então, que essa "disposição lúdica" suscitada pelo belo é um estado de completude e de liberdade para o homem.

Com base na concepção de arte como "liberdade", Henriqueta Lisboa deixa transparecer nos seus ensaios, nos prólogos e na sua poesia uma posição contrária ao didatismo imposto à produção de obras literárias voltadas para a criança e para o jovem no período em que escreve seus textos.

$\mathrm{Na}$ introdução da obra Literatura oral para a infância e a juventude: lendas, contos $e$ fábulas populares no Brasil (1969), Henriqueta ressalta que a abordagem dos textos populares na escola deve ser orientada por uma perspectiva livre de imposições:

[...] para ressalva do próprio fenômeno, o folclore não deve ser ministrado à infância a feitio de estudo, mas sim, proporcionado de modo recreativo, espontâneo, sem insistência. O que se define como popular, tradicional e anônimo não lograria viver em clima de imposição; mas pode conservar-se natural em terreno propício, à semelhança do fruto que amadurece fora da árvore, se o condiciona tratamento adequado. (LISBOA, 1969, p.12-13).

Nessa obra, Henriqueta Lisboa realizou um levantamento de contos, lendas, fábulas, mitos em livros e documentos dos principais folcloristas brasileiros: Couto de Magalhães (1837-1898), Sílvio Romero (1851-1914), Luís da Câmara Cascudo (1898-1986), dentre outros quinze folcloristas. Assim como nesta obra, no artigo "Folclore e literatura infantil" (LISBOA, 1974), a cultura popular, como era comum na época, aparece associada ao folclore e é concebida a partir de um olhar purista e saudosista:

Assim é que o folclore se desdobra em dois estágios definidos: o da inocência e o da sabedoria. [...] o legado ancestral se identifica com as almas simples e se deixa desvendar pelos espíritos laboriosos. De um lado as crianças e a massa popular, na tangência do primitivo; de outro lado os cientistas - etnólogos, etnógrafos, sociólogos, psicólogos e os puros folcloristas de laboratório ou de campo. (LISBOA, 1974, p.2).

$\mathrm{Na}$ visão de Henriqueta, cabe ao poeta o papel de "desvendar" as "esplêndidas reservas ainda intactas do nosso patrimônio folclórico":

Exatamente por ser um criador de mitos, o poeta poderá ser um recriador de outros mitos que não os de sua própria invenção. É lícito pensar que incube ao poeta a missão de imprimir a mitos difusos uma forma definitiva, de interpretar o segredo subjacente das mensagens primevas. Conhecedor da realidade humana em dimensões mais profundas que as habituais [...] (LISBOA, 1974, p. 2).

Ainda no prólogo da referida antologia, Henriqueta escreve sobre o papel da escola em relação às tradições culturais e a relevância da antologia para a realização do trabalho escolar:

É de notar que, em nosso meio, as amas já não recordam os contos de antigamente, e as mães já não repetem as lendas que ouviram na infância. Cabe, portanto, à escola, apta a reconhecer a importância dos valores tradicionais como forma educativa, o ofício de resguardar e transmitir tal patrimônio.[...] 
São estas as razões essenciais da organização de uma antologia da literatura oral corrente no país e que se destina a alcançar as crianças, de preferência por meio de seus educadores. (LISBOA, 1969, p. 12-13).

Para Henriqueta a instituição escolar é responsável pela transmissão "dos valores tradicionais como forma educativa. Assim, na visão da poetisa, a transmissão do patrimônio cultural, tornou-se uma atribuição da escola, representada na figura do professor, na época mais comumente da professora. Para ajudar nesta tarefa, a escritora organizou a antologia. Justifica-se assim o papel da escola e o da artista na formação cultural das crianças.

Assim como ocorre com o texto literário na tradição dos estudos brasileiros, as antologias são consideradas material eficaz para o ensino da língua: "Em longo e interessado convívio escolar, sempre me preocupou a falta de material literário com que lutam os professores (sic) para tornarem mais atraente e, pois, mais eficaz o ensino da língua." (LISBOA, 1969, p.11).

Na perspectiva de Henriqueta, entretanto, embora o texto literário seja tomado como pretexto para o estudo da língua, evidencia-se já uma preocupação com a compreensão das especificidades da linguagem literária. Na Antologia Literatura oral para a infância e a juventude (1969; 2002), ela destaca como orientação para o professor:

Ao serem deparados, por exemplo, certos deslizes gramaticais encontradiços na linguagem oral, torna-se indispensável, a par da achega corretiva, a ponderação da autenticidade psicológica desses supostos "erros", tão exatos na sua fôrça (Sic) de expressão estilística. (LISBOA, 1969, p.13).

Fica claro que, para Henriqueta, a arte, independentemente de quem a aprecie adulto ou criança - se reveste também de intencionalidade pedagógica, preocupada com os "valores fundamentais". No entanto, a finalidade pedagógica da arte não se limita a aprendizagem de modos de pensar e agir, estabelecidos pelo ideário burguês, mas compreende uma formação mais ampla capaz de despertar no leitor, o que Schiller chama de "impulso lúdico" - jogo entre as capacidades racionais e sensíveis do homem, e a ausência de regras ou conceitos para se alcançar a liberdade e a completude interior, ainda que esta jamais seja alcançada plenamente.

As antologias, organizadas pela escritora mineira, prioriza como critério principal, de acordo com Queirós (Apud, LISBOA, 2005, p.7), "a qualidade da obra, observando com rigor sua forma e excelência de seu conteúdo". Na Antologia poética para a infância e a juventude (1961, p. 7), Henriqueta declara que na escolha dos poemas priorizou a "força expressiva ao academismo", sua seleção norteou-se sem nenhum preconceito de escolas, tendências, meios ou épocas.

A preocupação com a qualidade revela também a concepção que Henriqueta tem de seus leitores. Para a poetisa, a criança, o adolescente e o jovem são sujeitos "sensíveis, espontâneos e inteligentes", conforme declara no prólogo da Antologia Poética para a Infância e a Juventude (1961).

Observamos também nas antologias que a organizadora elege como critério partir de autores e de obras de "data contemporânea para tempos mais remotos":

A sequência obedece a plano histórico, partindo de data contemporânea para tempos mais remotos, a fim de habituar o educando à diferenciação de métodos de estilo, variáveis com o temperamento individual e eventuais influxos de meio e de época. (LISBOA, s/d, p.9). 
Esta proposta de apresentação dos textos por períodos cronológicos, enfatizando a "fase contemporânea" e invertendo a ordem cronológica, é uma característica importante das antologias de Henriqueta, pois mostra o pioneirismo da escritora, uma vez que ainda hoje os compêndios de literatura para o ensino médio continuam elegendo como critério partir de autores e de obras do passado para o presente.

Já com relação à escolha dos textos, identificamos uma preocupação da organizadora em consagrar ou reunir tendências poéticas comuns entre poetas de uma ou várias gerações, na sua grande maioria pertencente ao cânone, conforme destaca na Antologia Escolar de Poemas para a Juventude: "Os poemas desta coletânea foram selecionados entre os mais expressivos da literatura de língua portuguesa e, em particular, das nossas letras." (LISBOA, s/d, p.9).

$\mathrm{Na}$ seleção dos autores, chama a atenção o fato de Henriqueta incluir nas suas antologias poetisas brasileiras e estrangeiras. Na Antologia Poética para a Infância e a Juventude encontram-se inclusos textos das escritoras: Celina Ferreira, Cecília Meireles, Ana Amélia de Queirós Carneiro de Mendonça, Francisca Júlia, Auta de Sousa, Gabriela Mistral, Florbela Espanca e Rosalía Castro. A incorporação das poetisas na antologia assinala o mérito da produção de autoria feminina "em uma época em que a criação literária ainda era considerada por muitos como prerrogativa dos homens" (TELLES, 2010, p. 403).

Observamos também nas antologias a preocupação em atingir o "interesse" do leitor infanto-juvenil. Na coletânea Antologia poética para a infância e a juventude, a poetisa admite que este livro representa o que ela gostaria de ter lido na infância:

Destinatário de sensibilidade distante da nossa, torna-se incógnita. Serão acessíveis tais poemas àqueles a quem os endereçamos? Mas quem lograra decifrar o mistério da comunicação artística?... Não é por certo no primeiro momento que percebemos todo o sentido da obra de arte, senão à medida em que a sua fruição nos atinge a natureza.

No esforço de servir a tão grande causa, é possível que me haja enganado em alguns pontos. Entretanto, posso dizer com sinceridade: é este o livro que eu desejaria ter lido na meninice. (LISBOA, 1961, p. 7-8).

O enxerto revela a preocupação da organizadora com o leitor, a quem inicialmente se destina a obra, colocando em cena, de maneira pioneira para a época, a reflexão sobre a escolha das obras a serem lidas em sala de aula e a importância da seleção adequada do texto literário para a formação estética dos sujeitos em formação. Numa perspectiva teórica sobre as antologias e a escola, Henriqueta engendra uma discussão que é imprescindível para a reflexão sobre a utilização da antologia escolar, distanciando-a do caráter pedagógico que a acompanha desde a sua origem. Desse modo, Henriqueta dá o pontapé inicial para esse debate que ainda perdura e tem desafiado professores, principalmente da educação básica na formação de leitores participativos, criativos e críticos.

\section{Considerações Finais}

A atuação de Henriqueta Lisboa como autora de poemas para crianças e como organizadora de antologias destinadas às crianças e aos jovens permite que percebamos a sua importância no âmbito da literatura destinada à infância. É possível perceber também que a educadora e a poetisa se complementam. A experiência no convívio diário em escolas secundárias durante anos possibilitou à poetisa um olhar sensato sobre a realidade da formação leitora de crianças e jovens no Brasil. Em meados da década de 1940, a educadora- 
poetisa ressalta que ensinar literatura não é forçar alguém a decorar datas e nomes: "Eu pensava que era difícil lecionar literatura; quando me impingiram no colégio, um amontoado de datas e de nomes, quase ia tomando horror daquilo que tanto me atraia desde criança. Esta lembrança tem me servido." (LISBOA, apud SOUZA, 2010, p.259).

A educadora conhecia o que os alunos liam e o que eles gostariam de ler. Já a poetisa foi capaz de perceber a educação estética para além do moralizante, vendo na poesia um instrumento de humanização que possibilita ao leitor a inserção em um mundo que instiga a reflexão e a sensibilidade, ao contrário da preocupação didática, marcada por um discurso de condução da criança, presente nas obras destinadas à infância no século XIX e primeiras décadas do século XX.

\section{Referências}

AZEVEDO, R. Prefácio. In: Literatura Oral para a Infância e a Juventude: Lendas, contos e Fábulas Populares do Brasil. São Paulo: Peirópolis, 2002.

GENS, R. M. Mulheres escrevem para criança (1890-1930). In: BRANDÃO, Izabel \& MUZART, Zahidé (Orgs). Refazendo Nós. Florianópolis: Editora Mulheres, 2003.

LISBOA, H. Poesia e didática In: Convívio Poético. Belo Horizonte: Imprensa Oficial, 1955. O peixe e o pássaro. Acervo dos Escritores Mineiros - Arquivo Henriqueta Lisboa Série Recortes (Sub-série HL n 270) na pasta n. 6, escrito em 1974.

1979.

Poesia: Minha profissão de fé. In: Vivência Poética: Belo Horizonte: São Vicente,

Antologia Poética para a infância e a juventude. Rio de Janeiro: Instituto Nacional do Livro, 1961.

Antologia Poética para a infância e a juventude. 2 ed. Rio de Janeiro: Edições de Ouro, 1966.

. Literatura Oral para a Infância e a Juventude: Lendas, contos e Fábulas Populares do Brasil. 3ed. São Paulo: Cultrix, 1970.

. Literatura Oral para a Infância e a Juventude: Lendas, contos e Fábulas Populares do Brasil. São Paulo: Peirópolis, 2002.

. Antologia Escolar de Poemas para a Juventude. 4 ed. São Paulo: Ediouro, S/d.

Antologia de Poemas Portugueses para a Juventude. São Paulo: Peirópolis, 2005.

NEVES, A. L. M. S. Um atalho, uma clareira, coisa assim, no caminho: reflexões sobre os lugares de Henriqueta Lisboa no contexto da literatura brasileira. (Tese de Doutorado). Defendida em 2014 na UFPB/João Pessoa.

QUEIRÓS, B. C. Henriqueta Lisboa Visita os Poetas de Portugal. (Prefácio). In: Antologia de Poemas Portugueses para a Juventude. São Paulo: Peirópolis, 2005. 
SCHILlER, F. A Educação Estética do Homem. Trad. Roberto Schwarz e Márcio Suzuki. São Paulo: Iluminuras, 1989.

TELLES, N. Escritoras, escritas, escrituras. In: DEL PRIORE, Mary (org.) História das mulheres no Brasil. 9 ed. São Paulo: Contexto, 2010.

Recebido em: agosto 2014.

Aprovado em: dezembro 2014. 